\title{
Autoimmune pancreatitis
}

\section{Introduction}

Autoimmune pancreatitis (AIP) is an infrequently disorder of apparently autoimmune etiology that is manifested with characteristic histologic, clinical, and morphologic findings that response to steroid treatment. ${ }^{1}$

AIP has been divided in type 1 and type 2. In type 1 AIP, the pancreas is densely infiltrated with immune cells and CD4 positive $\mathrm{T}$ cells, many of these plasma cells are IgG4 positive, in biopsy more than $10 \mathrm{IgG} 4$ positive cells per high-power field is consistent with the diagnosis of type 1 AIP, fibrosis is usually storiform and shows intra/ perivenular infiltration of lymphocytes and plasma cells often leading to obliterative phlebitis also known as lymphoplasmacytic sclerosing pancreatitis (LPSP). It may occur in an isolated pancreatic form or as part of a systemic IgG4-related disease.

Type 2 AIP is characterized by a different histologic pattern termed idiopathic duct-centric pancreatitis, that shows a granulocytic epithelial lesions with or without granulocytic acinar inflammation along with absent IgG4-positive cells $(0-10$ cells per high-power field), and without other organ involvement except for inflammatory bowel disease (approximately 15-30\%). ${ }^{2}$ The incidence remains unknown.

\section{Clinical manifestations}

The manifestations occur in the pancreas, biliary tract, and other organs. Patients commonly present with obstructive jaundice, abdominal pain, and/or biochemical evidence of pancreatitis. Type 1 (IgG4-related) presents at an older age (mean age of 70) than patients presenting with type 2 , and is more commonly in men (2-1). ${ }^{3}$ The most common initial presentation in both types is painless obstructive jaundice, other symptoms may include vomiting, weight loss, and glucose intolerance, abdominal pain is not a common symptom in type 1 but is common in type 2 .

Other organ involvement occur in around $60 \%$ of patient whit type 1 and include retroperitoneal fibrosis, biliary strictures (that mimic PSC and cholangiocarcinoma), hiliar lymphadenopathy, sclerosing sialoadenitis and nephritis. The radiographic features are similar for both types, US can shows a diffusely enlarged pancreas, and CT reveals a diffusely enlarged sausage-shaped pancreas. ${ }^{3}$

One of the hallmarks of both types is diffuse or segmental irregularity and narrowing of the main pancreatic duct. (4) In time this condition may lead to pancreatic gland atrophy and calcification

\section{Diagnosis}

There are several systems that have been proposed for the diagnosis of AIP including the Japanese Pancreas Society, an expert group from Korea, and the Mayo Clinic (HISORt mnemonic) in the United States. In 2011, an international panel of experts developed The International Consensus Diagnostic Criteria guidelines. ${ }^{4}$ This guidelines use 5 criteria: Pancreatic imaging of either parenchyma or ducts, serology, other organ involvement, histology of the pancreas and response to corticosteroid therapy. Depending on the mix of criteria present, this guideline allows to categorized patients as definitive o probable AIP. Efforts should be made to exclude pancreatic cancer. ${ }^{5}$
Volume 10 Issue I - 2019

Mario Lascarez-González, Esteban Ruiz-Blard
MD Máster in Clinical Investigation, University of costa Rica,
Costa Rica

Correspondence: Esteban Ruiz-Blard, MD in Clinical Investigation, University of costa Rica, Hospital San Vicente de Paúl, Heredia, Costa Rica, Tel (506) 8352-0I54,

Email estebanruizblard@gmail.com

Received: October 05, 2018 | Published: January 03, 2019

\section{Treatment}

Corticosteroid therapy is the mainstay of therapy for AIP, for improving symptoms and preventing long-term consequences, and it is usually effective within 2-4 weeks with rapid resolution of symptoms and radiographic abnormalities. Typically used regime is prednisone of $0.6 \mathrm{mg} / \mathrm{kg}$ to $1 \mathrm{mg} / \mathrm{kg}$ for 2 to 4 weeks with a taper of $5 \mathrm{mg} / \mathrm{d}$ every week.

Although most patients initially response to steroids, between 30$50 \%$ of patients with type 1 relapse once steroids are discontinued. Patience with type 2 relapse very rarely. This patients can be managed by a repeat course of prednisone followed by a low maintenance dose. ${ }^{3}$

Immunomodulator agents (eg, Thiopurines, rituximab, cyclosporine) have been used in patients with AIP who relapse following steroid withdrawal, fail steroid trial, or do not tolerate them. ${ }^{1,6}$

\section{Acknowledgments}

None.

\section{Conflicts of interest}

The author declares no conflicts of interest.

\section{References}

1. Madhani K, Farrell JJ. Autoimmune pancreatitis an update on diagnosis and management. Gastroenterol Clin N Am. 2016;45(1):29-43.

2. Okazaki K, Tomiyama T, Mitsuyama T, et al. Diagnosis and classification of autoimmune pancreatitis. Autoimmun Rev. 2014;13(4-5):451-458.

3. Kamisawa T, Chari ST, Lerch MM, et al. Recent advances in autoimmune pancreatitis: Type 1 and type 2. Gut. 2013;62(9):1373-1380.

4. Shimosegawa T, Chari ST, Frulloni L, et al. International consensus diagnostic criteria for autoimmune pancreatitis: guidelines of the International Association of Pancreatology. Pancreas 2011;40(3):352358.

5. Chari ST, Takahashi N, Levy MJ, et al. A diagnostic strategy to distinguish autoimmune pancreatitis from pancreatic cancer. Clin Gastroenterol Hepatol. 2009;7(10):1097-1103.

6. Hart PA, Topazian MD, Witzig TE, et al. Treatment of relapsing autoimmune pancreatitis with immunomodulators and rituximab: the Mayo Clinic experience. Gut. 2013;62(11):1607-1615. 